\title{
Bonafide, type-specific human papillomavirus persistence among HIV-positive pregnant women: predictive value for cytological abnormalities, a longitudinal cohort study
}

\author{
Angela RI Meyrelles ${ }^{1,2}$, Juliana D Siqueira ${ }^{3}$, Pâmela P dos Santos ${ }^{4}$, Cristina B Hofer ${ }^{5}$, \\ Ronir R Luiz ${ }^{6}$, Héctor N Seuánez ${ }^{3,7}$, Gutemberg Almeida ${ }^{1,2}$, Marcelo A Soares ${ }^{3,7}$, \\ Esmeralda A Soares ${ }^{3}$, Elizabeth S Machado ${ }^{5,7 /+}$
}

\footnotetext{
${ }^{1}$ Universidade Federal do Rio de Janeiro, Instituto de Ginecologia, Rio de Janeiro, RJ, Brasil ${ }^{2}$ Universidade Federal do Rio de Janeiro, Programa de Pós-Graduação em Ciências Cirúrgicas, Rio de Janeiro, RJ, Brasil ${ }^{3}$ Instituto Nacional de Câncer, Programa de Genética, Rio de Janeiro, RJ, Brasil ${ }^{4}$ Universidade Federal do Rio de Janeiro, Faculdade de Medicina, Rio de Janeiro, RJ, Brasil ${ }^{5}$ Universidade Federal do Rio de Janeiro, Instituto de Puericultura e Pediatria Martagão Gesteira, Rio de Janeiro, RJ, Brasil ${ }^{6}$ Universidade Federal do Rio de Janeiro, Instituto de Estudos em Saúde Coletiva, Rio de Janeiro, RJ, Brasil ${ }^{7}$ Universidade Federal do Rio de Janeiro, Departamento de Genética, Rio de Janeiro, RJ, Brasil
}

This study investigated the rate of human papillomavirus (HPV) persistence, associated risk factors, and predictors of cytological alteration outcomes in a cohort of human immunodeficiency virus-infected pregnant women over an 18-month period. HPV was typed through $\mathrm{L} 1$ gene sequencing in cervical smears collected during gestation and at 12 months after delivery. Outcomes were defined as nonpersistence (clearance of the HPV in the 2nd sample), re-infection (detection of different types of HPV in the 2 samples), and type-specific HPV persistence (the same HPV type found in both samples). An unfavourable cytological outcome was considered when the second exam showed progression to squamous intraepithelial lesion or high squamous intraepithelial lesion. Ninety patients were studied. HPV DNA persistence occurred in 50\% of the cases composed of type-specific persistence (30\%) or re-infection $(20 \%)$. A low CD4 $4^{+}$T-cell count at entry was a risk factor for type-specific, re-infection, or HPV DNA persistence. The odds ratio (OR) was almost three times higher in the type-specific group when compared with the re-infection group (OR =2.8; 95\% confidence interval: 0.43-22.79). Our findings show that bonafide (type-specific) HPV persistence is a stronger predictor for the development of cytological abnormalities, highlighting the need for HPV typing as opposed to HPV DNA testing in the clinical setting.

Key words: pregnancy - persistence - HPV - HIV

A high prevalence of certain human papillomavirus (HPV) types has been found in cervical cancer (CC) (zur Hausen 2009). The majority of HPV infections is transient and is cleared by the human host (Schmeink et al. 2013). In a minority of cases infection persists, increasing the chance of CC development (Ramanakumar et al. 2010), and several factors are associated with HPV persistence such as use of tobacco, oral contraceptives, and genetic susceptibility to infection (Wang \& Hildesheim 2003, Moscicki et al. 2012). HPV replication is essentially intraepithelial with little or no viraemia, therefore there is no inflammation and interferon response is blocked (Stanley 2010). The oncogenic potential of HPV types and variants is also a factor for persistence (Muñoz et al. 2003).

doi: 10.1590/0074-02760150393

Financial support: FAPERJ (E26/170.026/2008, E26/110.743/2013), $\mathrm{CNPq}(573806 / 2008-0)$, both under the auspice of the INCT for Cancer Control and CNPq 304169/2013-7 (for ESM)

ARIM and JDS contributed equally to this work.

+ Corresponding author: emachado@infolink.com.br Received 14 October 2015

Accepted 22 December 2015
Immunosuppression conditions caused by human immunodeficiency virus (HIV) infection (Kang \& Cu-Uvin 2012, Luz et al. 2012) and pregnancy (Palle et al. 2000, Nobbenhuis et al. 2002) are important factors that increase HPV acquisition, persistence, and development of CC. Pregnant women tend to have higher rates of progression from lesion to carcinoma during gestation and after delivery (Palle et al. 2000). Clearance of HPV is lower during the first two trimesters of pregnancy (Nobbenhuis et al. 2002). Interestingly, the additive effect of these two factors has been subject of controversy (Minkoff et al. 2006). There are some laboratory findings suggesting that degradation of $\mathrm{p} 53$ by HPV is more efficient when the codon 72 of TP53 encodes an arginine (Arg) residue. The Arg/Arg genotype was found to be more prevalent in $\mathrm{CC}$ biopsies and in individuals with progression from squamous intraepithelial lesions (SIL) to CC (Storey et al. 1998, Habbous et al. 2012), but the role of TP53 gene polymorphisms on the persistence of HPV infection is still controversy (Klug et al. 2009, Koshiol et al. 2009).

The cellular immunity to HPV involves $\mathrm{CD} 4^{+} \mathrm{T}$-cell responses and the contribution of $\mathrm{CD}^{+}$cytotoxic $\mathrm{T}$ cells. The use of combination antiretrovirals is expected to restore $\mathrm{CD}^{+} \mathrm{T}$-cell immunity in HIV-infected individuals, but fails to restore protective HPV-specific immunity because HPV antigen exposure occurs with little 
inflammation (Van der Burg \& Palefsky 2009). On the other hand, Blitz et al. (2013) showed that highly active antiretroviral therapy has a positive impact on clearance of high-risk (HR) HPV types.

There is a large variation in the definition of HPV persistence, both in time interval and in the molecular tests used to identify the infecting HPV. There is also a positive correlation between time span of HPV persistence and the risk of developing CC (Koshiol et al. 2008). Only a few studies addressed true, type-specific HPV persistence over time, especially in low and middle resource settings (Fukuchi et al. 2009, Datta et al. 2012).

We have previously showed the prevalence of HPV infection among HIV-infected pregnant women (Meyrelles et al. 2013). Data on persistence and type of persistence (type-specific vs. re-infection) after pregnancy are scarce in the literature (Nobbenhuis et al. 2002, Jalil et al. 2013). In the present study, we have analysed socio-demographic, clinical, and host/viral genetic factors associated with HPV persistence in this cohort. Clinical and molecular (type-specific) HPV persistence were compared and evaluated as predictors of cytological alteration outcomes over an 18-month period.

\section{SUBJECTS, MATERIALS AND METHODS}

Subjects and ethics - This was a prospective, longitudinal cohort study of HPV persistence involving $90 \mathrm{HPV}$ and HIV-infected pregnant women enrolled by the Program for HIV-infected Pregnant Women at Federal University of Rio Janeiro (UFRJ), Rio de Janeiro, Brazil, from April 2009 (1st enrollment) to July 2012 (last 18-month collection). HIV-positive serological status was confirmed by rapid HIV test or ELISA tests and a subsequent Western blot in distinct samples following recommendation by the Brazilian Ministry of Health. All women who agreed to participate signed an informed consent form before enrollment. The study was approved by the ethical committees of both centres involved in the study: UFRJ (protocols: 029/08 - Clementino Fraga Filho University Hospital; 18/10: Martagão Gesteira Childcare and Pediatrics Institute) and the National Cancer Institute (INCA) (protocol: 142/10).

This study was conducted in accordance with the ethical standards of the Brazilian National Ethical Committee as well as the Ethical Committee from the UFRJ and the INCA and with the Helsinki Declaration of 1975, as revised in 1983.

Samples and study variables - Cervical smears were collected at two different times from all 90 patients at the second trimester of gestation and 12 months after delivery [average of time interval: $17( \pm 4.5)$ months]. Collection was performed with two endocervical cytobrushes; one was placed in $100 \%$ ethanol for Pap smear diagnosis, while the other was placed into $1 \mathrm{ml}$ phosphate-buffered saline and sent to INCA for molecular analyses. A structured questionnaire containing demographic data, gynaecologic and obstetric history, and other risk factors for HPV infection was performed. Additional variables related to HIV infection have also been collected.
Sample processing and molecular analyses - Genomic and viral DNA was extracted with the QIAamp DNA mini kit (QIAGEN, USA) following manufacturer's specifications. A genome fragment of the HPV L1 gene was polymerase chain reaction (PCR)-amplified in a nested reaction with standard primers and conditions as previously described (Meyrelles et al. 2013). Host TP53 gene exon 4 (containing codon 72 of the predicted protein sequence) was also PCR-amplified as described elsewhere and used to assess DNA quality and integrity, thus validating the detection of HPV DNA (Meyrelles et al. 2013).

PCR products were purified and sequenced in a 3130XL Genetic Analyzer (Life Technologies, USA). Sequences were assembled and edited with SeqMan (DNAStar, USA). Sequences suggestive of multiple infections (electropherograms containing multiple peaks at definite positions) were subject to cloning into pMOS (GE Healthcare, USA) and transformation into Escherichia coli DH5 $\alpha$ competent cells according to the manufacturer's recommendations. An average of 10 bacterial colonies were sequenced and processed as described above to define each of the multiple HPV types.

HPV typing was performed by submitting edited bulk or clonal sequences to the Blast algorithm (ncbi.nlm.nih. gov/blast) and HPV types were assigned to the best hits of the database for each query sequence. Typing was further confirmed by phylogenetic analysis through clustering of query sequences to HPV type references. TP53 alleles and genotypes were classified by visual inspection of codon 72 of each sequence for the presence of a cytosine (coding for a proline residue) or a guanine (coding for Arg).

Definition of HPV oncogenic potential and HPV persistence - The HPV types 16, 18, 26, 30, 31, 33, 34, 35, $39,45,51,52,53,56,58,59,66,67,68,69,73$, and 82 were considered as HR types while HPV $6,11,40,42$, $43,44,54,61,70,72,81,89,32,62,74,83,84,86,87$, and 91 were defined as low-risk (LR) types (Muñoz et al. 2003, Várnai et al. 2007).

Nonpersistence was defined as the clearance of the HPV DNA in the second sample collected. Re-infection was defined as the detection of different types of HPV DNA in the two collected samples. Type-specific HPV persistence required the match of the HPV type found in both samples, either as major or minor strains (for the multiply-infected cases). Re-infection cases and typespecific HPV persistence were combined in the group denominated HPV DNA persistence. In case of multiple infections, each type was counted separately for determination of persistence rates.

Pap smear cytological classification and outcomes Cytological results of Pap smears were classified according to the 2001 Bethesda reporting guidelines (Solomon et al. 2002). Outcomes were considered as unfavourable when the second result showed the progression to low SIL (LSIL) or high SIL (HSIL).

Statistical analyses - All statistical evaluations were carried out with SPSS v.13. A descriptive analysis for calculating averages, medians, and standard deviations was conducted for continuous variables, while propor- 


\section{TABLE I}

Sociodemographic, clinical, and laboratorial characteristics of 90 human papillomavirus/human immunodeficiency virus (HIV) co-infected pregnant women

\begin{tabular}{|c|c|}
\hline Characteristic & $\mathrm{n}(\%)$ \\
\hline Age (years) $($ mean $\pm \mathrm{SD})$ & $27 \pm 6.3$ \\
\hline Age $\geq 25$ years & $56(62.2)$ \\
\hline Married/co-habitating status & $61(67.8)$ \\
\hline Complete primary education & $53(58.9)$ \\
\hline First sexual intercourse (years) (mean $\pm \mathrm{SD}$ ) & $15 \pm 2.4$ \\
\hline Parity $>1$ & $42(46.7)$ \\
\hline Past/present smoking & $35(38.9)$ \\
\hline Number of sexual partners $\geq 4$ & $56(62.2)$ \\
\hline Previous sexually transmitted diseases & $24(26.7)$ \\
\hline Past use of oral contraceptive & $47(52.2)$ \\
\hline Past use of condom & $25(27.8)$ \\
\hline Presence of ASC-US, LSIL, or HSIL in cytological smears at entry & $35(38.9)$ \\
\hline Presence of ASC-US, LSIL, or HSIL in cytological smears 1 year after delivery & $40(44.4)$ \\
\hline Pre-conception initiation of cART & $27(30)$ \\
\hline Median CD4 $4^{+} \mathrm{T}$-cell counts $\left(\right.$ cells $\left./ \mathrm{mm}^{3}\right)$ at entry $\left(\mathrm{IQR}_{50}\right)^{a}$ & $441(273-591)$ \\
\hline Median $\mathrm{CD}^{+} \mathrm{T}$-cell counts $\left(\right.$ cells $\left./ \mathrm{mm}^{3}\right)$ at delivery $\left(\mathrm{IQR}_{50}\right)^{b}$ & $526(354-691)$ \\
\hline $\mathrm{CD}^{+} \mathrm{T}$-cell counts $\left(\right.$ cells $\left./ \mathrm{mm}^{3}\right)>350 \mathrm{~mm}^{3} / \mathrm{mL}^{a}$ at entry & $47(56.6)$ \\
\hline $\mathrm{CD}^{+} \mathrm{T}$-cell counts $\left(\right.$ cells $\left./ \mathrm{mm}^{3}\right)>350 \mathrm{~mm}^{3} / \mathrm{mL}^{b}$ at delivery & $58(76.3)$ \\
\hline Median HIV VL $\left(\text { copies } / \mathrm{mL} ; \mathrm{IQR}_{50}\right)^{c}$ at entry & $1,085(78-8,827)$ \\
\hline \multicolumn{2}{|l|}{ TP53 codon 72 genotype } \\
\hline Arg/Arg & $35(38.9)$ \\
\hline Arg/Pro & $37(41.1)$ \\
\hline Pro/Pro & $18(20)$ \\
\hline
\end{tabular}

$a$ : missing seven patients; $b$ : missing 14 patients; $c$ : missing seven patients; Arg: arginine; ASC-US: atypical squamous cells of undetermined significance; cART: combination antiretroviral therapy; HSIL: high squamous intraepithelial lesions; IQR: interquartile range; LSIL: low squamous intraepithelial lesions; SD: standard deviation; VL: viral load.

tions were calculated for categorical variables. Univariate analyses were carried out using independent tests for variables following a normal distribution, and Wilcoxon (Mann-Whitney $U$ ) two-sample tests for those not following a normal distribution. Categorical variables were analysed with chi-square or Fisher's exact test. Variables with a $p$-value $\leq 0.20$ in the univariate analyses were included in a logistic regression analysis.

\section{RESULTS}

General cohort characteristics - One hundred and forty patients were enrolled. Twenty-eight patients (20\%) had no detected HPV DNA in their first sample and were not included in the analysis. In five patients $(3.6 \%)$, no DNA was recovered in the second sample suggesting lack of cells in the sample, and 17 (12.1\%) were lost to follow-up. Ninety patients were analysed.

Clearance of HPV infection occurred in 50\% (45 patients), type-specific persistence in 30\% (27 patients), and re-infection in $20 \%$ (18 patients). There was no difference in the time interval between the first and second sample collection among the three groups.
At study entry, the mean age of the cohort was $27 \pm 6$ years, and $62.2 \%$ were above 25 years of age. Sixty-eight percent were married or had a co-habitating status and $59 \%$ had completed primary education. The mean age of the first sexual intercourse was $15 \pm 2.4$ years, $53.3 \%$ being primiparous, and $62.2 \%$ had more than three sexual partners during life. Thirty-nine percent were smokers and $52 \%$ had used oral contraceptives. Past use of condom was observed in $28 \%$. Twenty-seven percent had reported previous sexually transmitted diseases and 39\% had abnormal cervical cytology at entry (atypical squamous cells of undetermined significance, LSIL, or HSIL); this number rose to $44.4 \%$ one year after delivery. Regarding HIV-1-related variables, $30 \%$ of the patients were on preconceptional combination antiretroviral therapy, the median $\mathrm{CD} 4^{+}$ T-cell counts at entry were $441 \mathrm{cells} / \mathrm{mm}^{3}$ and almost $57 \%$ had counts above 350 cells $/ \mathrm{mm}^{3}$, the median HIV viral load (VL) was 1,085 copies per $\mathrm{mL}$ of plasma (Table I).

TP53 genotypes at codon 72 were distributed as $38.9 \%$ Arg/Arg homozygous, 20\% Pro/Pro homozygous, and $41.1 \% \mathrm{Arg} /$ Pro heterozygous. 
TABLE II

Distribution of human papillomavirus (HPV)

types and number of infections in the first sample and their associated persistence at 18 months

\begin{tabular}{|c|c|c|}
\hline $\begin{array}{l}\text { HPV type at } \\
\text { first sample }\end{array}$ & $\begin{array}{c}\text { Cases } \\
\text { (n)t }\end{array}$ & $\begin{array}{c}\text { Type-specific persistence } \\
\mathrm{n}(\%)\end{array}$ \\
\hline HPV16 & 35 & $9(25.7)$ \\
\hline HPV58 & 11 & $4(36.4)$ \\
\hline HPV35 & 5 & $1(20)$ \\
\hline HPV53 & 5 & $2(40)$ \\
\hline HPV66 & 4 & $0(0)$ \\
\hline HPV73 & 4 & $1(25)$ \\
\hline HPV31 & 3 & $0(0)$ \\
\hline HPV45 & 3 & $0(0)$ \\
\hline HPV69 & 3 & $0(0)$ \\
\hline HPV82 & 3 & $0(0)$ \\
\hline HPV18 & 2 & $2(100)$ \\
\hline HPV33 & 2 & $0(0)$ \\
\hline HPV52 & 2 & $0(0)$ \\
\hline HPV56 & 2 & $2(100)$ \\
\hline HPV67 & 1 & $1(100)$ \\
\hline HPV68 & 1 & $0(0)$ \\
\hline HPV81 & 6 & $1(33.3)$ \\
\hline HPV83 & 6 & $2(16.7)$ \\
\hline HPV62 & 5 & $2(40)$ \\
\hline HPV06 & 3 & $1(33.3)$ \\
\hline HPV55 & 2 & $0(0)$ \\
\hline HPV61 & 2 & $0(0)$ \\
\hline HPV11 & 1 & $0(0)$ \\
\hline HPV32 & 1 & $0(0)$ \\
\hline HPV42 & 1 & $0(0)$ \\
\hline HPV44 & 1 & $0(0)$ \\
\hline HPV70 & 1 & $1(100)$ \\
\hline HPV72 & 1 & $0(0)$ \\
\hline HPV84 & 1 & $0(0)$ \\
\hline
\end{tabular}

in boldface: high-risk HPV types.

HPV typing and persistence - Twenty-nine different HPV types were identified at baseline (Table II). Of those, 16 were classified as HR and 13 as LR types. Overall, 73 patients $(81.1 \%)$ were infected by HR types, either as mono or multiple infections. Eighteen patients (20\%) had detectable multiple infections and in 15 of those $(83.3 \%)$ HR types were present.

The most prevalent HR HPV type found at baseline was HPV 16, present in 35 infections (29.9\%), followed by HPV 58 (11 cases), HPV 35 and 53 (5 cases), and HPV 73 and 66 (4 cases). HPV 18, consensually recognised as associated to cervical oncogenesis (Muñoz et al. 2003), was only present in two infections $(1.7 \%)$. With respect to LR types, HPV 83 and HPV 81 were the most prevalent ( 6 cases each; 5.1\%), followed by HPV 62 (5 cases; 4.3\%) and HPV 6 (3 cases; $2.6 \%$ ).
HPV DNA persistence was found in 45 patients (50\%): 27 women $(30 \%)$ presented a type-specific persistence, while re-infection with another HPV type occurred in 18 women $(20 \%)$. Table II depicts all cases of type-specific persistence. The total number of infections was low for most individual HPV types found and though we were unable to draw conclusions about type-specific persistence efficiency, some interesting results are noteworthy. HPV 16 and 58, the two most common HR types found, persisted in 26 and $36 \%$ of the cases, respectively. Several highly oncogenic HR types (e.g., HPV 66, 45, 31, 69 and 82) did not persist in any infection, despite being present in only three to four cases each. Finally, HPV 18 and HPV 56 persisted in the two infections where they were detected at baseline. Regarding the LR types, those with the highest persistence rates were HPV 70 (100\%), followed by HPV 62 (40\%), HPV 6, and HPV 81 (33.3\% each).

Risk factors for HPV persistence - We have evaluated factors associated with HPV persistence for the three defined groups (HPV clearance, re-infection, and type-specific persistence (Table III) and odds ratio (OR) for type-specific persistence or re-infection (Table IV). The total number of type-specific persistence or re-infection cases was low, therefore precluding us from performing multivariate analyses. Age of first sexual intercourse $>15$ years, past use of oral contraceptive, lack of condom use, $\mathrm{CD}^{+}$T-cell counts $<350$ cells $/ \mu \mathrm{L}$, and a high HIV VL at study entry were associated with HPV DNA persistence. Only $\mathrm{CD}^{+} \mathrm{T}$-cell counts $<350$ cells $/ \mu \mathrm{L}$ was an independent risk factor for HPV DNA persistence $[\mathrm{OR}=4.6 ; 95 \%$ confidence interval (CI): 1.00-21.3].

Cytological outcomes based on HPV persistence The proportion of patients who showed unfavourable outcomes increased from the nonpersistent (cleared) HPV infections to re-infections and then to type-specific persistence, being the highest in the latter group. In the nonpersistent group, there were six LSIL and two HSIL in the first sample and all cases improved in the second sample. Four new cases of LSIL were seen. In the re-infection group, there were eight LSIL at baseline with two improvements and two new cases of LSIL in the follow-up. In type-specific group, initial sample showed 13 LSIL and two HSIL. In the follow-up, three LSIL evolved to HSIL and four new cases of LSIL developed. The OR was almost three times higher in the type-specific group when compared with the re-infection group $(\mathrm{OR}=2.8$; 95\% CI: 0.43-22.79).

\section{DISCUSSION}

In this study, we analysed $90 \mathrm{HIV} / \mathrm{HPV}$ co-infected, pregnant women for rate of persistence of HPV after delivery and risk factors associated with persistence over 18 months. Overall, over $80 \%$ of the studied women were infected by HR HPV types at baseline. HPV DNA persistence occurred in $50 \%$ of the women after 18 months, but only in $30 \%$ showed type-specific persistence. The remaining 18 patients $(20 \%)$ were rather re-infected by different HPV types, and do not correspond to bonafide HPV persistence. The use of sequencing methodology to classify the different types of HPV has enable us to 
TABLE III

Factors associated with human papillomavirus (HPV) clearance, re-infection, or type-specific persistence $(n=90)$

\begin{tabular}{|c|c|c|c|c|}
\hline & $\begin{array}{c}\text { Clearance } \\
(\mathrm{n}=45)\end{array}$ & $\begin{array}{l}\text { Re-infection } \\
\quad(\mathrm{n}=18)\end{array}$ & $\begin{array}{l}\text { Type-specific persistence } \\
\qquad(\mathrm{n}=27)\end{array}$ & \\
\hline Variable & $\mathrm{n}(\%)$ & $\mathrm{n}(\%)$ & $\mathrm{n}(\%)$ & $\mathrm{p}$ \\
\hline Age $\geq 25$ years & $26(57.8)$ & $10(55.6)$ & $20(74.1)$ & 0.312 \\
\hline Age of first sexual intercourse $\leq 15$ years & $33(73.3)$ & $10(55.6)$ & $13(48.1)$ & 0.083 \\
\hline Parity $>1$ & $23(51.1)$ & $8(44.4)$ & $11(40.7)$ & 0.679 \\
\hline Married/co-habitating & $32(71.1)$ & $6(33.3)$ & $23(85.2)$ & 0.001 \\
\hline Completed primary education & $31(68.9)$ & $7(38.9)$ & $15(55.6)$ & 0.084 \\
\hline Past/present smoking & $14(31.1)$ & $9(50)$ & $12(44.4)$ & 0.297 \\
\hline Number of sexual partners $\geq 4$ & $27(60)$ & $11(61.1)$ & $18(66.7)$ & 0.848 \\
\hline Previous sexually transmitted disease & $9(20)$ & $8(44.4)$ & $7(25.9)$ & 0.142 \\
\hline Past use of oral contraceptive & $18(40)$ & $11(61.1)$ & $18(66.7)$ & 0.063 \\
\hline Past use of condom & $17(37.8)$ & $3(16.7)$ & $5(18.5)$ & 0.105 \\
\hline Pre-conception use of cART & $13(28.9)$ & $2(11.1)$ & $12(44.4)$ & 0.056 \\
\hline $\mathrm{CD}^{+}{ }^{+} \mathrm{T}$-cell counts $>350 \mathrm{cel} / \mathrm{mm}^{3}$ at entry ${ }^{a}$ & $30(75)$ & $6(37.5)$ & $11(40.7)$ & 0.005 \\
\hline $\mathrm{CD}^{+} \mathrm{T}$-cell counts $>350 \mathrm{cel} / \mathrm{mm}^{3}$ at delivery ${ }^{b}$ & $33(84.6)$ & $10(76.9)$ & $15(62.5)$ & 0.144 \\
\hline HIV VL $(\log \geq 4)$ at entry ${ }^{c}$ & $12(28.6)$ & $9(56.3)$ & $13(52)$ & 0.065 \\
\hline Codon 72 of TP53 & & & & 0.563 \\
\hline Arg/Arg & $18(40)$ & $5(27.8)$ & $12(44.4)$ & \\
\hline Arg/Pro & $20(44.4)$ & $7(38.9)$ & $10(37)$ & \\
\hline Pro/Pro & $7(15.6)$ & $6(33.3)$ & $5(18.5)$ & \\
\hline
\end{tabular}

$a$ : missing CD4 counts at entry, seven patients; $b$ : missing CD4 counts at delivery, 14 patients; $c$ : missing human immunodeficiency vírus (HIV) viral load (VL) at entry, seven patients; Arg: arginine; cART: combination antiretroviral therapy; in boldface: ignificant $\mathrm{p}$-values at the 0.05 level.

determine the true rate of infecting HPV types and avoid overestimation of HPV persistence.

Our HPV typing approach has enabled us to evaluate all cases of persistence by individual HPV types. Of note, the relative efficiency of HPV persistence by types 16 and 58 was possible to infer in view of the higher number of cases in our cohort. HPV 58 appears to persist with higher efficiency than HPV 16 (36\% vs. $26 \%$ of the infections, respectively), although statistically significance has not been achieved. Finally, despite only four cases of infection were observed, two of HPV 18 and two of HPV 56, both types persisted in the period analysed, highlighting its potential in the faster development of cervical abnormalities, as suggested by others (Rintala et al. 2012), and CC. We observed diverse rates of persistence among the 13 LR HPV types, albeit lower than the observed rates for HR types. In two patients, the persistence of LR types occurred with concomitant infection with HR types. Of five patients with exclusively LR HPV type infections (HPV 81 and 62), two had an LSIL lesion in the first cytological exam that persisted and another patient developed LSIL during follow-up (HPV 70). We are currently cloning those cases to exclude the presence of HR types as minority species, and also confirming the cytological exam diagnosis through biopsy, but those results may indicate LR HPV types with enhanced persistence potential.
We find a higher prevalence of TP53 genotypes encoding proline at codon 72 in our patients $(60 \%)$ which is in accordance with the genotype among highly mixed populations (Klug et al. 2009). Although no correlation of genotypes with HPV persistence was observed, the small sample size might account for the absence of correlation. In a study with Latin women from Costa Rica, genotypes containing proline (Pro/Arg or Pro/Pro) had an 1.3 and 1.8fold increased risk for developing grade 3 cervical intraepithelial dysplasia/persistence, respectively, when compared with the Arg/Arg genotype (Koshiol et al. 2009).

An important issue to be considered in HPV persistence studies is the timespan and the definition of persistence. HPV persistence is regularly defined as having two or more HPV DNA positive tests and test intervals greatly vary between studies, complicating comparative analyses (Rositch et al. 2013). Additional factors, such as considering only HR HPV types, and defining type-specific or only HPV DNA for persistence analyses, further preclude accurate HPV persistence estimates. In a recent meta-analysis that included 86 distinct HPV persistence studies, the mean HPV testing interval was 9.8 months, whereas the authors estimate that approximately half of the HPV infections persist past six-12 months. Therefore, we think the test interval used herein (18 months) is appropriate and decreases the chance of overestimating persistence or re-infection. 


\section{TABLE IV}

Logistic regression analysis of factors associated with human papillomavirus (HPV) type-specific persistence or re-infection

\begin{tabular}{|c|c|c|c|c|}
\hline \multirow[b]{2}{*}{ Variable } & \multicolumn{2}{|l|}{$\begin{array}{l}\text { Type-specific } \\
\text { persistence }\end{array}$} & \multicolumn{2}{|l|}{ Re-infection } \\
\hline & OR & $\mathrm{p}$ & OR & $\mathrm{p}$ \\
\hline \multicolumn{5}{|l|}{ Age (years) } \\
\hline$<25$ & 1 & 0.16 & 1 & 0.87 \\
\hline$\geq 25$ & $2.08(0.73-5.90)$ & & $0.91(0.30-2.75)$ & \\
\hline \multicolumn{5}{|c|}{ Age of first sexual intercourse (years) } \\
\hline$\leq 15$ & 1 & 0.03 & 1 & 0.17 \\
\hline$>15$ & $2.96(1.09-8.08)$ & & $2.20(0.70-6.89)$ & \\
\hline \multicolumn{5}{|l|}{ Parity } \\
\hline $0-1$ & $1.52(0.58-3.99)$ & 0.39 & $1.30(0.44-3.92)$ & 0.63 \\
\hline$>1$ & 1 & & 1 & \\
\hline \multicolumn{5}{|l|}{ Status marital } \\
\hline Single/widow/divorced & $0.43(0.12-1.48)$ & 0.17 & $4.92(1.52-15.91)$ & 0.006 \\
\hline Married/co-habitating & 1 & & 1 & \\
\hline \multicolumn{5}{|l|}{ Primary education } \\
\hline Uncompleted & $1.77(0.66-4.75)$ & 0.25 & $3.48(1.12-10.86)$ & 0.03 \\
\hline Completed & 1 & & 1 & \\
\hline \multicolumn{5}{|l|}{ Past/present smoking } \\
\hline No & 1 & 0.25 & 1 & 0.16 \\
\hline Yes & $1.77(0.66-4.75)$ & & $2.21(0.72-6.78)$ & \\
\hline \multicolumn{5}{|l|}{ Number of sexual partners } \\
\hline $1-3$ & 1 & 0.57 & 1 & 0.94 \\
\hline$\geq 4$ & $1.33(0.49-3.62)$ & & $1.05(0.34-3.21)$ & \\
\hline \multicolumn{5}{|c|}{ Previous sexually transmitted disease } \\
\hline No & 1 & 0.56 & 1 & 0.06 \\
\hline Yes & $1.40(0.45-4.33)$ & & $3.20(0.98-10.44)$ & \\
\hline \multicolumn{5}{|l|}{ Past use of oral contraceptive } \\
\hline No & 1 & 0.03 & 1 & 0.13 \\
\hline Yes & $3.0(1.11-8.14)$ & & $2.36(0.77-7.22)$ & \\
\hline \multicolumn{5}{|l|}{ Past use of condom } \\
\hline No & $2.67(0.82-8.38)$ & 0.09 & $3.03(0.77-12.05)$ & 0.10 \\
\hline Yes & 1 & & 1 & \\
\hline \multicolumn{5}{|l|}{ Preconception use of cart } \\
\hline No & $0.51(0.19-1.38)$ & 0.18 & $3.25(0.65-16.18)$ & 0.20 \\
\hline Yes & 1 & & 1 & \\
\hline \multicolumn{5}{|l|}{ CD4 T-cell at entry ${ }^{a}$} \\
\hline$\leq 350$ & $4.36(1.53-12.46)$ & 0.005 & $5.00(1.45-17.27)$ & 0.008 \\
\hline$>350$ & 1 & & 1 & \\
\hline CD4 T-cell at delivery ${ }^{b}$ & & 0.05 & & \\
\hline$\leq 350$ & $3.30(0.99-10.95)$ & & $1.65(0.35-7.82)$ & 0.67 \\
\hline$>350$ & 1 & & 1 & \\
\hline \multicolumn{5}{|l|}{ HIV VL at entry ${ }^{c}$} \\
\hline $\log 1-3$ & 1 & 0.06 & 1 & 0.05 \\
\hline $\log \geq 4$ & $2.70(0.97-7.60)$ & & $3.21(0.97-10.60)$ & \\
\hline Codon 72 of p53 & & 0.83 & & 0.27 \\
\hline Arg/Arg & $1.33(0.47-3.82)$ & & $0.79(0.21-2.95)$ & \\
\hline Arg/pro & 1 & & 1 & \\
\hline Pro/pro & $1.43(0.36-5.66)$ & & $2.45(0.61-9.82)$ & \\
\hline
\end{tabular}

$a$ : missing CD4 counts at entry, 7 patients; $b$ : missing CD4 counts at delivery, 14 patients; $c$ : missing human immunodeficiency virus (HIV) viral load (VL) at entry, 7 patients; Arg: arginine; in boldface, significant p-values at the 0.05 level; OR: odds ratio. 
As mentioned above, HPV persistence has been associated with development of cytological abnormalities and progression to neoplasia. To evaluate the impact of HPV persistence on the progression of cytological abnormalities, we have compared the cytological outcomes of the women throughout the 18-month analysed period. Our study suggests that type-specific HPV persistence has a better predictive value to cervical lesion progression and its use should be reinforced over traditional HPV persistence assays.

The present study has some important limitations. One of them is the lack of histopathologic confirmation of the cytologic abnormalities through biopsy. Another limitation was the low HPV persistence rates which precludes us from performing a detailed analyses of the type-specific and re-infection groups. Nevertheless, we showed the importance of identification of specific HPV types for the discrimination between bonafide persistence and clearance followed by re-infection. Measurements of true incidence of new HPV infections in subjects is a difficult task, because they can be infected by new viruses and clear them over the time period spanning two collection times, and those transitory infections will not be detected. However, by addressing type-specific HPV persistence, we can at least get better estimates of new infections, excluding those cases where the HPV types differ between the two timepoints analysed. Additional re-infection cases may also be excluded if the two viruses are genetically different, even if belonging to the same HPV type, an analysis that requires full-length genome sequencing and phylogenetic estimates, procedures that we did not conduct in this study.

HPV persistence is a risk factor for the development of cervical intraepithelial neoplasia and cervical carcinoma, whereas persistence by HR types is a prerequisite for those conditions (zur Hausen 2000). HIV-infected women are at particularly higher risk of HPV infection; likewise, pregnancy is a condition for increased prevalence of HPV (Hernández-Girón et al. 2005) and for faster progression from SIL to carcinoma (Palle et al. 2000). The contribution of each of these factors to cervical carcinogenesis is not completely understood, but both promote immune suppression and changes in the hormonal milieu (Hernández-Girón et al. 2005), influencing viral acquisition and persistence.

We have found HPV persistence of 50\% after delivery in our cohort. Reports of persistence after pregnancy are scarce and it decreases with longer time of follow-up. Castellsagué et al. (2009) found a HPV persistence of $46.2 \%$ among pregnant women in six week postpartum samples. Jalil et al. (2013) reported persistence in a later time point (average of 6 months after delivery) of 51.9\% and 53.6\% among HIV-infected and HIV-uninfected pregnant women for some types. In both reports approximately $28.5 \%$ were infected by untyped HPV. Nobbenhuis et al. (2002) reported persistence of $31 \%$ for HR types, after an average of six months after delivery. Our study is the first to assess clearance of HPV after delivery describing all types involved in the infection and with a clear definition of bonafide or re-infection persistence.
The HPV type 16 was the most prevalent type in this cohort and type 58 was the second most common type found. In a meta-analysis of HPV prevalence in five continents, type 58 was the third most common type in Latin America and Caribbean. In relation of type-specific persistence, our results confirm previous evidence found in a recent longitudinal survey of the Finish Family HPV Study, where HPV 58 showed a higher persistence time compared to HPV 16 (Louvanto et al. 2010). These results call our attention that type 58 should be included among specific primers used to detect HPV, at least in our region.

Our results corroborate previous report showing that low $\mathrm{CD} 4^{+} \mathrm{T}$-cell counts are associated with HPV persistence (Kang \& Cu-Uvin 2012), and illustrate the important role of cellular immune responses in the control and clearance of HPV infection (Frazer 2009). HIV-infected women with a CD $4<200$ cells $/ \mathrm{mm}^{3}$ have almost two times more chance of HPV persistence when compared with those with a CD4 T-cell counts $>500$ cells $/ \mathrm{mm}^{3}$ (Ahdieh et al. 2001).

In conclusion, the results herein highlight the importance of HPV persistence in the setting of immunosuppressed patients and their associated risk factors. In addition, efforts to implement true type-specific HPV identification in persistence should be made to avoid overestimation of persistence and to more accurately predict risk for cytological abnormalities and cervical carcinoma in HPV-infected women.

\section{ACKNOWLEDGEMENTS}

To patients who agreed in participate in the study, and to Laura Reis, Leila Monnerat, and Kelly Lobo, at the DNA Sequencing Core of the INCA, for technical assistance.

\section{REFERENCES}

Ahdieh L, Klein RS, Burk R, Cu-Uvin S, Schuman P, Duerr A, Safaeian M, Astemborski J, Daniel R, Shah K 2001. Prevalence, incidence, and type-specific persistence of human papillomavirus in human immunodeficiency virus (HIV)-positive and HIVnegative women. J Infect Dis 184: 682-690.

Blitz S, Baxter J, Raboud J, Walmsley S, Rachlis A, Smaill F, Ferenczy A, Coutlée F, Hankins C, Money D, Canadian Women's HIV Study Group 2013. Evaluation of HIV and highly active antiretroviral therapy on the natural history of human papillomavirus infection and cervical cytopathologic findings in HIV-positive and high-risk HIV-negative women. J Infect Dis 208: 454-462.

Castellsagué X, Drudis T, Cañadas MP, Goncé A, Ros R, Pérez JM, Quintana MJ, Muñoz J, Albero G, de Sanjosé S, Bosch FX 2009. Human papillomavirus (HPV) infection in pregnant women and mother-to-child transmission of genital HPV genotypes: a prospective study in Spain. BMC Infect Dis 9: 74.

Datta P, Bhatla N, Pandey RM, Dar L, Patro AR, Vasisht S, Kriplani A, Singh N 2012. Type-specific incidence and persistence of HPV infection among young women: a prospective study in North India. Asian Pac J Cancer Prev 13: 1019-1024.

Frazer IH 2009. Interaction of human papillomaviruses with the host immune system: a well evolved relationship. Virology 384: 410-414.

Fukuchi E, Sawaya GF, Chirenje M, Magure T, Tuveson J, Ma Y, Shiboski S, Da Costa M, Palefsky J, Moscicki AB, MakunikeMutasa R, Chipato T, Smith-McCune KK 2009. Cervical human papillomavirus incidence and persistence in a cohort of HIV-negative women in Zimbabwe. Sex Transm Dis 36: 305-311. 
Habbous S, Pang V, Eng L, Xu W, Kurtz G, Liu FF, Mackay H, Amir E, Liu G 2012. p53 Arg72Pro polymorphism, HPV status and initiation, progression, and development of cervical cancer: a systematic review and meta-analysis. Clin Cancer Res 18: 6407-6415.

Hernández-Girón C, Smith JS, Lorincz A, Lazcano E, HernándezÁvila M, Salmerón J 2005. High-risk human papillomavirus detection and related risk factors among pregnant and nonpregnant women in Mexico. Sex Transm Dis 32: 613-618.

Jalil EM, Bastos FI, Melli PP, Duarte G, Simões RT, Yamamoto AY, Morais RA, Quintana SM 2013. HPV clearance in postpartum period of HIV-positive and negative women: a prospective follow-up study. BMC Infect Dis 13: 564.

Kang M, Cu-Uvin S 2012. Association of HIV viral load and CD4 cell count with human papillomavirus detection and clearance in HIV-infected women initiating highly active antiretroviral therapy. HIV Med 13: 372-378.

Klug SJ, Ressing M, Koenig J, Abba MC, Agorastos T, Brenna SM, Ciotti M, Das BR, Del Mistro A, Dybikowska A, Giuliano AR, Gudleviciene Z, Gyllensten U, Haws AL, Helland A, Herrington CS, Hildesheim A, Humbey O, Jee SH, Kim JW, Madeleine MM, Menczer J, Ngan HY, Nishikawa A, Niwa Y, Pegoraro R, Pillai MR, Ranzani G, Rezza G, Rosenthal AN, Roychoudhury S, Saranath D, Schmitt VM, Sengupta S, Settheetham-Ishida W, Shirasawa H, Snijders PJ, Stoler MH, Suárez-Rincón AE, Szarka K, Tachezy R, Ueda M, van der Zee AG, Doeberitz MK, Wu MT, Yamashita T, Zehbe I, Blettner M 2009. TP53 codon 72 polymorphism and cervical cancer: a pooled analysis of individual data from 49 studies. Lancet Oncol 10: 772-784.

Koshiol J, Hildesheim A, Gonzalez P, Bratti MC, Porras C, Schiffman M, Herrero R, Rodriguez AC, Wacholder S, Yeager M, Chanock SJ, Burk RD, Wang SS 2009. Common genetic variation in TP53 and risk of human papillomavirus persistence and progression to CIN3/ cancer revisited. Cancer Epidemiol Biomarkers Prev 18: 1631-1637.

Koshiol J, Lindsay L, Pimenta JM, Poole C, Jenkins D, Smith JS 2008. Persistent human papillomavirus infection and cervical neoplasia: a systematic review and meta-analysis. Am J Epidemiol 168: 123-137.

Louvanto K, Rintala MA, Syrjanen KJ, Grenman SE, Syrjanen SM 2010. Genotype-specific persistence of genital human papillomavirus (HPV) infections in women followed for 6 years in the Finnish Family HPV Study. J Infect Dis 202: 436-444.

Luz PM, Velasque L, Friedman RK, Russomano F, Andrade AC, Moreira RI, Chicarino-Coelho J, Pires E, Veloso VG, Grinsztejn B 2012. Cervical cytological abnormalities and factors associated with highgrade squamous intraepithelial lesions among HIV-infected women from Rio de Janeiro, Brazil. Int J STD AIDS 23: 12-17.

Meyrelles AR, Siqueira JD, Hofer CB, Costa TP, Azevedo AP, Guimarães BV, Seuánez HN, Soares MA, Almeida G, Soares EA, Machado ES 2013. HIV/HPV co-infection during pregnancy in southeastern Brazil: prevalence, HPV types, cytological abnormalities, and risk factors. Gynecol Oncol 128: 107-112.

Minkoff H, Shen X, Watts DH, Leighty R, Hershow R, Palefsky J, Tuomala R, Neu N, Zorrilla CD, Paul M, Strickler H 2006. Relationship of pregnancy to human papillomavirus among human immunodeficiency virus-infected women. Obstet Gynecol 108: 953-960.

Moscicki AB, Schiffman M, Burchell A, Albero G, Giuliano AR, Goodman MT, Kjaer SK, Palefsky J 2012. Updating the natural history of human papillomavirus and anogenital cancers. Vaccine 30 (Suppl. 5): F24-33.
Muñoz N, Bosch FX, de Sanjosé S, Herrero R, Castellsagué X, Shah $\mathrm{KV}$, Snijders PJ, Meijer CJ, International Agency for Research on Cancer Multicenter Cervical Cancer Study Group 2003. Epidemiologic classification of human papillomavirus types associated with cervical cancer. $N$ Engl J Med 348: 518-527.

Nobbenhuis MA, Helmerhorst TJ, van den Brule AJ, Rozendaal L, Bezemer PD, Voorhorst FJ, Meijer CJ 2002. High-risk human papillomavirus clearance in pregnant women: trends for lower clearance during pregnancy with a catch-up postpartum. $\mathrm{Br} J$ Cancer 87: 75-80.

Palle C, Bangsboll S, Andreasson B 2000. Cervical intraepithelial neoplasia in pregnancy. Acta Obstet Gynecol Scand 79: 306-310.

Ramanakumar AV, Goncalves O, Richardson H, Tellier P, Ferenczy A, Coutlée F, Franco EL 2010. Human papillomavirus (HPV) types $16,18,31,45$ DNA loads and HPV-16 integration in persistent and transient infections in young women. BMC Infect Dis 10: 326.

Rintala MA, Louvanto K, Rantanen V, Grenman SE, Syrjanen KJ, Syrjanen SM 2012. High-risk human papillomavirus associated with incident cervical intraepithelial neoplasia developing in mothers in the Finnish Family HPV Study cohort. Scand J Infect Dis 44: 115-125.

Rositch AF, Koshiol J, Hudgens MG, Razzaghi H, Backes DM, Pimenta JM, Franco EL, Poole C, Smith JS 2013. Patterns of persistent genital human papillomavirus infection among women worldwide: a literature review and meta-analysis. Int J Cancer 133: 1271-1285.

Schmeink C, Massuger L, Lenselink C, Quint WG, Witte BI, Berkhof J, Melchers WJ, Bekkers RL 2013. Prospective follow-up of 2,065 young unscreened women to study human papillomavirus incidence and clearance. Int J Cancer 133: 172-181.

Solomon D, Davey D, Kurman R, Moriarty A, O'Connor D, Prey M, Raab S, Sherman M, Wilbur D, Wright Jr T, Young N, Forum Group Members, Bethesda 2001 Workshop 2002. The 2001 Bethesda System: terminology for reporting results of cervical cytology. JAMA 287: 2114-2119.

Stanley M 2010. HPV - immune response to infection and vaccination. Infect Agent Cancer 5: 19.

Storey A, Thomas M, Kalita A, Harwood C, Gardiol D, Mantovani F, Breuer J, Leigh IM, Matlashewski G, Banks L 1998. Role of a p53 polymorphism in the development of human papillomavirusassociated cancer. Nature 393: 229-234.

Van der Burg SH, Palefsky JM 2009. Human immunodeficiency virus and human papilloma virus - why HPV-induced lesions do not spontaneously resolve and why therapeutic vaccination can be successful. J Transl Med 7: 108.

Várnai AP, Bollmann M, Bánkfalvi A, Griefingholt H, Pfening N, Schmitt C, Pajor L, Bollmann R 2007. The spectrum of cervical diseases induced by low-risk and undefined-risk HPVS: implications for patient management. Anticancer Res 27: 563-570.

Wang SS, Hildesheim A 2003. Chapter 5: viral and host factors in human papillomavirus persistence and progression. $J$ Natl Cancer Inst Monogr 31: 35-40.

zur Hausen H 2000. Papillomaviruses causing cancer: evasion from host-cell control in early events in carcinogenesis. J Natl Cancer Inst 92: 690-698.

zur Hausen H 2009. Papillomaviruses in the causation of human cancers - a brief historical account. Virology 384: 260-265. 